\title{
REVIEW
}

\section{Epidemiology of COPD}

\author{
C. Raherison* and P.O. Girodet ${ }^{\#}$
}

\begin{abstract}
Chronic obstructive pulmonary disease (COPD) is responsible for early mortality, high death rates and significant cost to health systems. The projection for 2020 indicates that COPD will be the third leading cause of death worldwide (from sixth in 1990) and fifth leading cause of years lost through early mortality or handicap (disability-adjusted life years) (12th in 1990). Active smoking remains the main risk factor, but other factors are becoming better known, such as occupational factors, infections and the role of air pollution. Prevalence of COPD varies according to country, age and sex. This disease is also associated with significant comorbidities. COPD is a disorder that includes various phenotypes, the continuum of which remains under debate. The major challenge in the coming years will be to prevent onset of smoking along with early detection of the disease in the general population.
\end{abstract}

KEYWORDS: Chronic obstructive pulmonary disease, epidemiology, morbidity, mortality, (cigarette) smoking

hronic obstructive pulmonary disease $(\mathrm{COPD})$ is a chronic respiratory disorder that progresses slowly and is characterised by an obstructive ventilatory pattern, which is rarely reversible, very often related to tobacco smoking and which can lead to chronic respiratory failure. This definition covers, in reality, a number of entities, as follows.

1) Chronic bronchitis, with an obstructive ventilatory pattern that is defined by the existence of chronic bronchitis with permanent obstruction of airways (forced expiratory volume in $1 \mathrm{~s}$ (FEV1) to forced vital capacity (FVC) ratio $<70 \%$ )

2) Chronic respiratory failure, which is defined by the existence of chronic obstructive bronchitis with hypoxaemia.

3) Emphysema, which is defined at the anatomical level by destruction of the walls of the alveolar sacs/ducts beyond the terminal bronchiole with an abnormal increase in size of distal airways [1]. Centrolobular emphysema is a result of the dilation or destruction of respiratory bronchioles. It is a form of emphysema associated with cigarette smoking. Panlobular emphysema is more often associated with a deficit in $\alpha_{1}$-antitrypsin, and is the result of dilation or destruction of all the lobules [2]. It should be noted that centrolobular and panlobular emphysema can be mutually associated.

It is, therefore, a diverse group of conditions with a common functional characteristic, that of an obstructive ventilatory disorder that is rarely reversible.

In this paper we shall review the tools used in epidemiological studies to assess the scale of the problem, given the emergence of COPD over the past $20 \mathrm{yrs}$ in both developed and developing countries. Although the main cause is active smoking, from now on we need to consider the occurrence of COPD as the clinical consequence of an interaction between environmental factors on the one hand and the existence of a not yet properly understood genetic predisposition on the other. It is a disorder that is still underdiagnosed, and is sometimes diagnosed too late. Improvement in management must be based on early detection and early cessation of smoking in order to reduce the decline in respiratory function, for which current pharmacological treatment is ineffective.

What is the objective of an epidemiological study in COPD? If it is to screen COPD patients in the population in order to prevent a pejorative prognosis, it needs simple and robust tools to identify subjects with an obstructive ventilatory condition even if they have few symptoms. If the objective is research on COPD risk factors, it is necessary to have specific and sensible adapted tools (i.e. questionnaires and/or biological or environmental measures).

\section{ESTIMATE OF PREVALENCE OF COPD}

From the point of view of methodology, the studies published are based on diverse definitions,
AFFILIATIONS

*Dept of Respiratory Diseases, CHU Bordeaux, Institute of Public Health, Epidemiology and Development, University of Bordeaux 2, and ${ }^{\#}$ Dept of Pharmacology, $\mathrm{CHU}$ Bordeaux, University of Bordeaux 2, Bordeaux, France.

CORRESPONDENCE

C. Raherison

Dept of Respiratory Diseases,

Haut-Lévèque,

CHU Bordeaux, EA 3672, Institute of Public Health, Epidemiology and Development

University of Bordeaux 2

146 rue Léo Saignat

33076 Bordeaux

France

E-mail: chantal.raherison@chu-

bordeaux.fr

Received:

June 022009

Accepted after revision:

Sept 092009

PROVENANCE

Submitted article, peer reviewed. 
the bases for which are either symptoms, a diagnosis made by a doctor or spirometric data.

Questionnaires on respiratory health have been issued by the International Union against Tuberculosis and Lung Disease [3] and the European Community Respiratory Health Survey (ECRHS) [4]. The questions used correspond to the clinical definition of chronic bronchitis, i.e. morning cough and sputum, and are based on the British Medical Research Council Questionnaire. Although these questionnaires have been validated for asthma, the method of reference chosen was the presence of bronchial hyperreactivity, with the objective of measuring the prevalence of asthma and related symptoms, and not chronic bronchitis.

These questionnaires have, for the most part, been used in the general population, in samples of young adults thought to be representative of these populations.

It can, therefore, be considered that, contrary to asthma, the questionnaires used in epidemiological studies of COPD are derived from clinical experience, but have never been validated.

In clinical practice, accurate history taking is undertaken first, then clinical examination and, lastly, functional testing. In primary care, an important issue is how to define airflow obstruction, i.e. how to conclude that the given test is normal or abnormal. Without exception, guidelines recommend using a post-bronchodilator FEV1/FVC ratio $<0.70$ to define irreversible airflow obstruction, whatever the age and the sex of the patients [5]. This approach is recognised to be easy to perform; however, it must be appreciated that this advantage should be balanced against the disadvantage of possible false diagnoses. It is already known that using pre-bronchodilator spirometry can overestimate COPD prevalence by as much as 30\% [6]. In primary care, SCHERMER et al. [7] showed in a large population of patients $(n=14,056)$ that this ratio overestimates airflow obstruction in middle-aged and elderly patients. The proportion of false-positive diagnoses using the fixed ratio $<0.70$ was: $8.9 \%$ in $31-40$ yr age stratum; $15.5 \%$ for those aged $41-50$ yrs; $23.9 \%$ for those aged $51-60 \mathrm{yrs} ; 33.2 \%$ for those aged $61-70 \mathrm{yrs}$; $38.7 \%$ for those aged $71-80 \mathrm{yrs}$; and, finally, $42.7 \%$ for those aged over 81 yrs [7]. Other papers have reported an overdiagnosis; HANSEN et al. [8] reported overdiagnosis of $20 \%$ and SWANNEY et al. [9] reported false-positive rates of up to $60 \%$.

In epidemiological studies, the challenge is to estimate accurately the prevalence of COPD and using the correct definition is very important in order to avoid misclassification biases. The Burden of Obstructive Lung Disease (BOLD) study is an international effort to collect population-based estimates of the prevalence of COPD using standardised methods, including 14 sites with 10,000 adults aged $\geqslant 40$ yrs old [10]. Recently, they published the impact on prevalence estimates of using the fixed ratio versus various other spirometry-based definitions of COPD [11].

Prevalence based on fixed ratio criteria is significantly higher than for all other estimators, whatever the geographic site. Adjusting the FEV1/FVC ratio for normative ageing effects appears to reduce the false-positive rate reported in ageing patients. Finally, they showed that the use of the FEV1/FEV6 ratio in place of FEV1/FVC when using the lower limit of normal (LLN) and FEV1 $<80 \%$ predicted had little impact. The authors recommend a definition based on an $\mathrm{FEV} 1 / \mathrm{FVC}$ ratio less than the LNN, and an FEV1 either $<80 \%$ pred or below the LLN.

Recently, the American Thoracic Society (ATS)/European Respiratory Society (ERS) statement recommends using the LLN of the FEV1/FVC in place of using the fixed ratio FEV1/ FVC $<70 \%$, which is defined as 1.645 standard deviations below the predicted value [12]

As the LLN appeared to be able to more precisely estimate abnormal values, equations used to calculate FEV1/FVC and FEV1 values need to be periodically revised [13].

A meta-analysis of studies of the general population published between 1990 and 2004 revealed geographical disparities and differing methodologies [14].

The prevalence of COPD was estimated to be $7.6 \%$ (95\% CI 6$9.2 \%$ ) independent of the defined diagnostic criteria (table 1). On the basis of 38 studies, the prevalence of chronic bronchitis was estimated to be $6.4 \%$ (95\% CI $5.3-7.7 \%$ ). The prevalence of emphysema (via chest radiograph) was estimated to be $1.8 \%$ (95\% CI 1.3-2.6\%) on the basis of eight studies.

The majority of the studies $(62 \%)$ concerned patients over 40 yrs of age, in particular those aged between 40 and 64 yrs. The prevalence of COPD increases with age, with a five-fold increased risk for those aged over 65 yrs compared with patients aged less than 40 yrs [15].

The prevalence of COPD increases with smoking status (by a factor of five), but it needs to be emphasised that prevalence of COPD in nonsmokers was $4 \%$, suggesting the existence of other risk factors, such as passive smoking, or factors of occupational exposure (table 2).

COPD affects twice as many males as females but this difference will diminish, given the fact that more and more females

\begin{tabular}{llc} 
TABLE 1 & $\begin{array}{l}\text { Estimate of prevalence according to diagnostic } \\
\text { criteria }\end{array}$ \\
Criteria & Surveys n & $\begin{array}{c}\text { Pooled prevalence } \\
\% \mathbf{( 9 5 \% ~ C l )}\end{array}$ \\
\hline COPD & 37 & $7.6(6-9.5)$ \\
Spirometry & 26 & $9.2(7.7-11)$ \\
Reported by patient & 7 & $4.9(2.8-8.3)$ \\
Diagnosed by a doctor & 4 & $5.2(3.3-7.9)$ \\
Clinical/radiological examination & 1 & $13.7(12.9-14.5)$ \\
Chronic bronchitis & 38 & $6.4(5.3-7.7)$ \\
Productive moist cough & 29 & $6.7(5.4-8.2)$ \\
Reported by patient & 15 & $5.3(3.9-7.1)$ \\
Emphysema & 8 & $1.8(1.3-2.6)$ \\
Clinical/radiological examination & 1 & $3.2(2.8-3.6)$ \\
Reported by patient & 7 & $1.7(1.2-2.5)$ \\
\hline \\
COPD: chronic obstructive pulmonary disease. Modified and reproduced from \\
[14] with permission from the publisher.
\end{tabular}




\begin{tabular}{|c|c|c|c|}
\hline \multirow[t]{2}{*}{ TABLE 2} & \multicolumn{3}{|c|}{$\begin{array}{l}\text { Prevalence of chronic obstructive pulmonary } \\
\text { disease according to demographic criteria }\end{array}$} \\
\hline & Studies $\mathrm{n}$ & $\begin{array}{l}\text { Cumulative prevalence } \\
\qquad \%(95 \% \mathrm{Cl})\end{array}$ & $\mathrm{p}$-value \\
\hline All & 37 & $7.6(6-9.5)$ & \\
\hline Age & & & $<0.0001$ \\
\hline$<40 \mathrm{yrs}$ & 9 & $3.1(1.8-5)$ & \\
\hline$\geqslant 40 \mathrm{yrs}$ & 34 & $9.9(8.2-11.8)$ & \\
\hline $40-64$ yrs & 23 & $8.2(6.5-10.3)$ & \\
\hline$\geqslant 65 \mathrm{yrs}$ & 11 & $14.2(11-18)$ & \\
\hline Status & & & $<0.0001$ \\
\hline Active smoker & 17 & $15.4(11.2-20.7)$ & \\
\hline Ex-smoker & 16 & $10.7(8.1-14)$ & \\
\hline Nonsmoker & 16 & $4.3(3.2-5.7)$ & \\
\hline Sex & & & 0.0002 \\
\hline Male & 27 & $9.8(8-12.1)$ & \\
\hline Female & 27 & $5.6(4.4-7)$ & \\
\hline Geographic zone & & & 0.77 \\
\hline Africa & 0 & & \\
\hline America & 3 & $4.6(2.8-7.6)$ & \\
\hline Europe & 28 & $7.4(5.9-9.3)$ & \\
\hline South-east Asia & 2 & $11.4(4.4-26.4)$ & \\
\hline Pacific & 4 & $9(3-24.1)$ & \\
\hline Sample & & & 0.04 \\
\hline Urban & 12 & $10.2(7.4-13.9)$ & \\
\hline Rural & 4 & $8(3.9-15.8)$ & \\
\hline Mixed & 21 & $6.1(4.9-7.7)$ & \\
\hline
\end{tabular}

throughout the world have taken up smoking in the past few years in developed countries, and that nonsmoking females are exposed to biomass combustion products in developing countries. However, the studies based on spirometric measurements are somewhat skewed. For instance, the prevalence of COPD also varied according to successive classifications (i.e. Global Initiative for Chronic Obstructive Lung Disease (GOLD), ERS and ATS). In addition, the diagnostic criterion used in $25 \%$ of cases was the GOLD II criteria, and approximately one third of studies were based on the post-bronchodilator FEV1. Lastly, the criteria of quality concerning spirometric measures were not available in these studies, but in the future more rigorously defined and standardised criteria should enable a better estimate of prevalence. In general, the studies using objective criteria report a higher prevalence of COPD than those based on the answers of patients to questionnaires. Likewise, the surveys based on the diagnosis made by a doctor reported a higher prevalence than those based on the symptoms reported by patients.

There are geographical disparities, with a higher prevalence of COPD in South-east Asia (12.5\%), but it should be noted that there is an absence of data available concerning a large part of the world (the African continent and countries around the Mediterranean), for the majority of studies are concerned with Europe.

The studies carried out in Africa and in Asia have enabled an estimate of the prevalence of chronic bronchitis to be made, but not on the basis of spirometric data because of a lack of spirometers in general practice [16]. The definition of cases of COPD is problematic in these countries where the prevalence of respiratory infections, such as tuberculosis, is high and patients often have both risk factors: they have a tubercular disease and are cigarette smokers. The prevalence of moderate to severe COPD was modelled in 12 South-east Asian countries and estimated to be $6.3 \%$, with maximum prevalence in China $(6.5 \%)$ and in Vietnam (6.7\%) [16]. The data concerning Africa is only partial, involving pockets of population exposed in mining regions, agricultural areas or in hospital environments. The prevalence of chronic bronchitis in nonexposed workers varied from $3.5 \%$ to $17 \%$, and was higher in exposed workers (4.1\% to $38.5 \%)$. One South African study in 1998 involved 14,000 adults over 15 yrs old. Prevalence of chronic bronchitis was estimated to be $2.3 \%$ for males and $2.8 \%$ for females.

In South America, the PLATINO study enabled the prevalence of COPD in those aged over 40 yrs to be estimated at between $7.8 \%$ and $20 \%$ [17]. The spirometric criteria were those of GOLD (post-bronchodilator FEV1/FVC $<70 \%$ ). Nonresponders were principally males, thus constituting a predominantly female population included in the study.

In France, one of the first studies undertaken estimated the prevalence of chronic bronchitis in 2002 to be $4 \%$ in a sample representative of the French population of subjects aged over 25 yrs $(n=14,076)$ [18]. Underdiagnosis was also revealed because only $24 \%$ of subjects with symptoms had had chronic bronchitis diagnosed by a doctor. In the ECRHS, from a sample of 9,839 adults, the prevalence of COPD according to the GOLD classification (2001) was estimated to be: $9.2 \%$ (stage 0); $1 \%$ (stage I); and $0.5 \%$ (stage II-III). Mean age was 33 yrs, with $28.5 \%$ of smokers consuming $<15$ pack-yrs and $30 \%$ consuming $\geqslant 15$ pack-yrs. This study identified a group of young subjects at risk of developing COPD, who had already had recourse to treatment relating to respiratory problems. Within the framework of longitudinal follow-up in this international survey, 5,000 adults with no clinical elements to indicate asthma, aged 20-44 yrs in 1992 were seen again in 2000. The incidence of COPD was 2.8 cases per 1,000 population per annum. Chronic cough and sputum were risk factors for COPD independent of smoking (OR 1.85, 95\% CI 1.17-2.93). The subjects who had presented a moist cough and/or sputum during the first follow-up had a risk multiplied by three (RR $2.88,95 \%$ CI $1.44-5.79$ ) of presenting COPD 8 yrs later [19].

The worldwide study (BOLD project) provided a unique opportunity to estimate the prevalence of COPD in population based-samples in adults aged more than $40 \mathrm{yrs}$ old, in both developed countries and developing countries, using a standardised protocol for questionnaires and lung function testing. Each geographic site agreed to recruit 600 adults (300 males and 300 females). At the 12 sites, 9,425 participants completed the questionnaire and performed post-bronchodilator spirometry. The prevalence (with standard error) of patients at stage II or more can be estimated at $10.1 \pm 4.8 \%$; $11.8 \pm 7.9 \%$ for males and $8.5 \pm 5.8 \%$ for females, with heterogeneity across centres and sex [10]; however, the fairly high prevalence of COPD in females and in subjects who had never smoked suggest that other exposures could be implicated, and suggest the a greater genetic predisposition in females. 


\section{Points to remember}

COPD is a frequent disorder, which remains difficult to estimate because of the variability of methods used in the various studies.

The presence of cough and/or sputum production identifies a group at risk of presenting COPD (in those $\geqslant 40 \mathrm{yrs}$ and smoking $\geqslant 10$ pack-yrs)

Using LLN seems to be more accurate for COPD diagnosis, than fixed ratio FEV1/FVC.

\section{SCREENING FOR COPD}

Early screening for COPD is based on early detection by a general practitioner. Some authors have developed the application of scores to increase detection of COPD by using spirometers in general practice [20]. The objective of screening is to detect with accuracy airflow obstruction even in patients with few symptoms. Thus, validity of screening in COPD depends directly on the validity of airflow obstruction.

Sensitivity, specificity and positive and negative predictive values were calculated for the fixed FEV1/FVC ratio, considering LLN definition as the gold standard for assessment of airflow obstruction [7]. Sensitivity was $97.9 \%$, specificity $91.2 \%$, positive predictive value $72 \%$ and negative predictive value $99.5 \%$ for both males and females.

The agreement between the two definitions for the subgroup of current and ex-smokers aged $\geqslant 50$ yrs was better for the most severe patients. Screening for COPD was based on carrying out a free spirometric test on patients considered to be at risk for COPD, i.e. those aged at least 40 yrs and having a cigarette consumption of $\geqslant 10$ pack-yrs. In this population $(n=110,355)$ the mean age was 53 yrs. Bronchial obstruction was defined in relation to a FEV1/FVC $<70 \%$. Screening enabled a diagnosis of chronic obstruction in $20.3 \%$ of subjects. In terms of severity, $7.6 \%$ had mild obstruction (FEV1 $\geqslant 70 \%$ pred), $6.7 \%$ moderate obstruction (FEV1 50-69\% pred), and 5.9\% severe obstruction $(<50 \%$ pred). Among patients with severe obstruction, no diagnosis by a doctor had previously been made. The prevalence of bronchial obstruction increased with age and the level of smoking. As far as symptoms were concerned, $52.5 \%$ of participants presented a moist cough and sputum, whereas the respiratory function was normal [21].

Future challenges in screening COPD will be to update prediction equations so that the most reliable LLN can be obtained.

Detection of COPD may provide opportunities for early interventions, including smoking cessation, that may improve quality of life and survival.

\section{Points to remember}

COPD is underdiagnosed, including in young people. Screening criteria for COPD need to fulfil validity criteria in the general population.

\section{IMPACT OF COPD ON MORBIDITY}

In diagnosed patients, COPD is a disabling disorder which is accompanied by a negative impact on quality of life, including in patients aged over 40 yrs with mild obstruction [22]. The factors significantly associated with a poor quality of life are: severity of respiratory damage, estimated by FEV1; the use of oxygen treatment; the frequency of visits to the emergency room; and the frequency of hospitalisation.

The impact, in terms of cost and consumption of treatment, is significant and includes: medical prescriptions, consultations, visits to the emergency room and hospitalisation.

In 2001, according to the white book published by the ERS, the annual cost of COPD was estimated to be $€ 38.7$ billion, with $73 \%$ of costs being related to inability to work, $12 \%$ to ambulatory care, $7.5 \%$ to hospitalisation, and $7.5 \%$ to medication [23]. In France, the mean direct annual cost per patient was estimated to be $€ 4,366.41 \%$ of this cost was directly related to medical care and follow-up of the patient, $25 \%$ to medical care of exacerbations, and 34\% to other associated disorders. $33 \%$ of the cost was related to hospitalisation and $31 \%$ directly to prescriptions for medication [24]. In Europe, the annual cost per patient varies from $€ 151$ to $€ 3,912$ [25].

In addition, the weight of comorbidities which are frequently associated with COPD is important to consider. It is estimated that approximately two-thirds of patients with COPD have one or two comorbidities. The main comorbidities present are cardiovascular disorders, bronchial cancer, lung infections, thromboembolic disorders [26], the existence of associated asthma, high blood pressure, osteoporosis, joint pain, gastroduodenal ulcer, depression and anxiety [27]. Table 3 shows the principal comorbidities frequently associated with COPD by aetiology [28].

\begin{tabular}{l} 
TABLE 3 Principal comorbidities associated with chronic \\
obstructive pulmonary disease \\
Cardiovascular \\
Coronary artery disease \\
High blood pressure \\
Left heart failure \\
Tachyarrhythmia \\
Malignant tumours \\
Nonsmall cell lung cancer \\
Respiratory \\
Pneumonia \\
Pulmonary embolism \\
Chronic cor pulmonale \\
Asthma \\
Rhinitis \\
Endocrine \\
Obesity \\
Diabetes \\
Dyslipidaemia \\
Denutrition \\
Gastroenterology \\
Gastric ulcer \\
Gastro-oesophageal reflux \\
Osteoarticular \\
Fractures \\
Osteoporosis \\
Psychiatric \\
Depression \\
Anxiety \\
\hline
\end{tabular}


In another study published by BARR et al. [29], among 1,003 patients with COPD, $61 \%$ reported moderate or severe dyspnoea and $41 \%$ reported a prior hospitalisation for COPD. The most prevalent comorbid diagnoses were hypertension (55\%), hypercholesterolaemia (52\%), depression $(37 \%)$, cataracts $(31 \%)$ and osteoporosis (28\%).

\section{MORTALITY ATTRIBUTABLE TO COPD}

According to the World Health Organization, COPD is the fourth leading cause of death in the world, with approximately 2.75 million deaths per annum, or $4.8 \%$ of deaths. In Europe, mortality rates vary from country to country: $<20$ per 100,000 population in Greece, Sweden, Iceland and Norway, up to more than 80 per 100,000 population in Ukraine and in Romania. In France, the mortality rate is approximately 40 deaths per 100,000 population [30]. In developing countries, mortality is also on the increase, in relation to the increase in cigarette smoking. In China, tobacco is responsible for $12 \%$ of deaths, with projections which show that this rate could reach $30 \%$ in 2030 [31].

Mortality from COPD is higher in males and increases with age in those over 45 yrs old. Mortality also increases with severity of disease. In the USA, within the framework of the National Health and Nutrition Examination Survey (NHANES I), 1,301 deaths were analysed in a cohort of 5,542 adults. The presence of COPD at various GOLD stages was associated with the following risk of death, as defined by hazard ratio (HR). Stage I: HR 1.4, 95\% CI 1.31-1.70; stage II: HR 2.04, 95\% CI 1.34-3.11; severe COPD: HR 2.7, 95\% CI 2.1-3.5 [32].

Several factors have been found to be predictive of mortality in patients with COPD: severity of airflow obstruction, nutritional status (body mass index), exercise capacity using the 6-min walk test and severity of dyspnoea (the BODE index). This index appears to predict mortality better than the FEV1 alone [33]. The mortality rate during hospitalisation for exacerbation of COPD is estimated to be $2.5-10 \%$. The mortality rate after hospitalisation varies between $16 \%$ and $19 \%$ in the 3 months following hospitalisation, between $23 \%$ and $43 \%$ at $1 \mathrm{yr}$ and is $55-60 \%$ at 5 yrs. After classifying patients by GOLD stage,

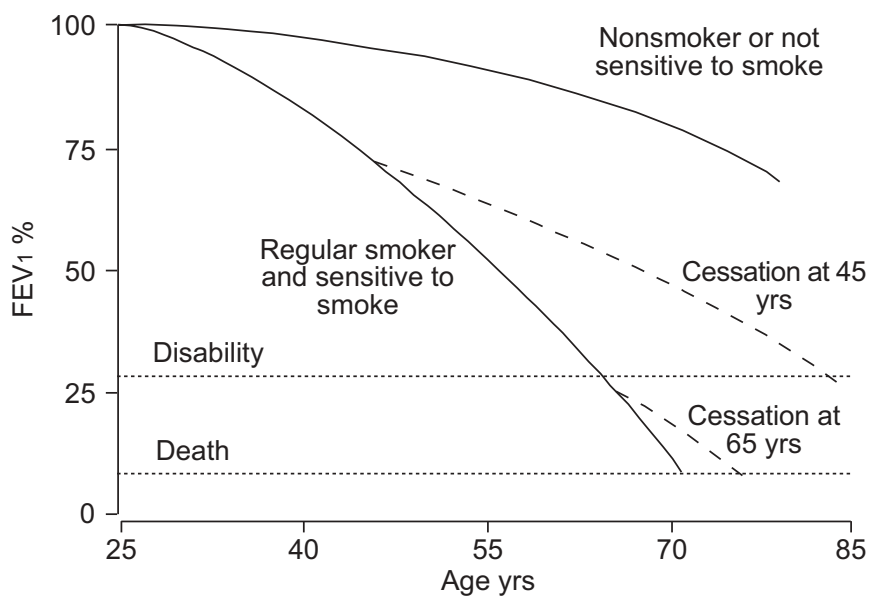

FIGURE 1. Decrease in forced expiratory volume in $1 \mathrm{~s}(\mathrm{FEV} 1)$ according to smoking status. Adapted from [37] mortality rate at 5 yrs was $17 \%$ for stage I, $42 \%$ for stage II, $49 \%$ for stage III and $73 \%$ for stage IV [23].

In France, an analysis of cause of death in subjects aged over 45 yrs revealed that in 2002 COPD represented 3\% of deaths. The diagnosis of COPD was associated in $48 \%$ of subjects with other causes of death. Between 1979 and 1999, the trend in rate of mortality remained stable in males and increased in females [34].

The only factors having demonstrated a reduction in mortality in COPD are cessation of smoking [35] and oxygen treatment [36] for patients with chronic respiratory failure (fig. 1).

\section{RISK FACTORS FOR COPD}

Risk factors are directly related to the interaction existing between genetic predisposition and exposure to environmental factors. The clinical manifestations resulting from this interaction will also depend on the existence of associated comorbidities.

\section{Active and passive smoking}

Active smoking is the main risk factor for COPD. The risk attributable to active smoking in COPD is thought to vary from $40 \%$ to $70 \%$ according to the country. Figure 2 shows that the prevalence of chronic bronchitis increases with smoking and with age. It should be noted that, at the time of this study, there was a small proportion of patients with chronic bronchitis despite the fact that they were nonsmokers [15].

Active smoking by females during pregnancy will also alter fetal lung development and be responsible for asthma in predisposed children [38]. In addition, consequence of passive smoking is the lateness in lung development of the fetus.

The mechanisms of action of the components of cigarette smoke on lung tissue and parenchyma are probably multiple. Many arguments arising from in vitro and ex vivo experiments are in favour of an inflammation of the airways, where the cell and molecular agents differ from those present in asthma. Histological analyses of bronchial biopsies from patients with mild to moderate COPD show the presence of an infiltrate of CD8+ lymphocytes in proximal airways. Neutrophils are present in high concentrations in the sputum of patients with COPD [39]. In addition, cigarette smoke directly stimulates various types of cells, in particular macrophages [40,41] and epithelial cells of the airways [42], thus contributing to increased production of mediators and cytokines that participate in maintaining the inflammatory reaction. Through their interactions with the epithelium and extracellular matrix, the bronchial smooth muscle cells would also appear to play an important role in the remodelling of the airways observed in COPD [43].

Other theories have been established to try and explain the irreversible histological lesions caused by tobacco components. For example, an imbalance in proteases/antiproteases is thought to lead to the destruction of compounds in the extracellular matrix, in particular elastin. This concept remains controversial and is based on an original study demonstrating a $40 \%$ alteration in the function of an antiprotease, $\alpha_{1-}$ antitrypsin, in subjects who were smokers, in comparison to those who were nonsmokers [44]. Finally, there is a permanent antagonism between the toxicity of oxidants present in cigarette smoke and the antioxidant immune system. The 


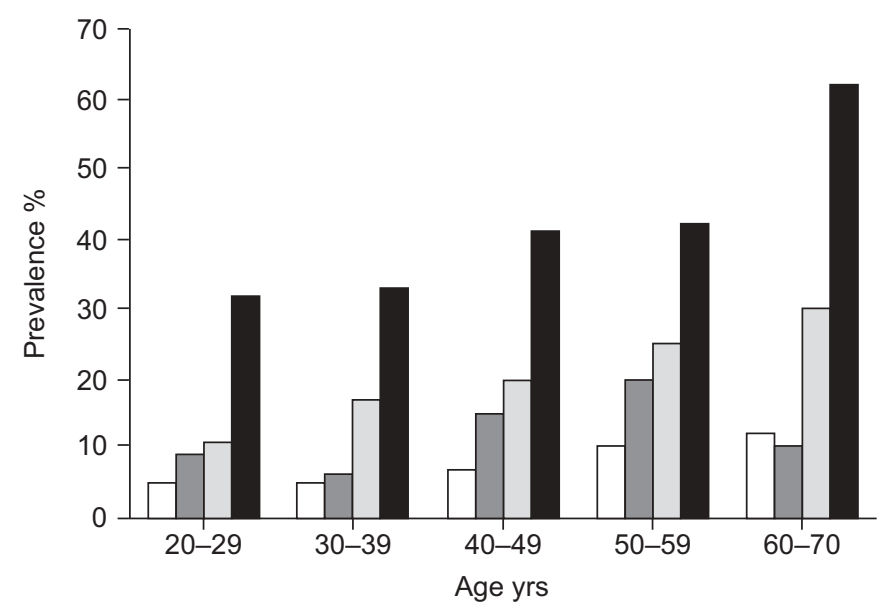

FIGURE 2. Prevalence of chronic bronchitis in relation to active smoking, stratified by age. $\square$ : nonsmokers; $\square:$ : 1-10 cigarettes per day; $\square:$ : 11-20 cigarettes per day; : $>20$ cigarettes per day. Reproduced from [15] with permission from the publisher.

upset in this oxidant-antioxidant balance results in oxidative stress, the presence of which has been shown in subjects who were smokers and patients with COPD [45].

\section{Genetic factors}

Although cigarette smoking represents the most important risk factor, not all smokers develop COPD in their lifetime, which implies that genetic factors may be involved [46]. Generally, it would seem that the respiratory function of a child is determined by the respiratory function of both of its parents. Thus, among children whose parents have a low respiratory function (last quintile), 37\% will have a comparatively low respiratory function. Conversely, among children whose parents have a normal or high respiratory function, $41 \%$ will have a normal function [47].

At present, only a severe deficit in $\alpha_{1}$-antitrypsin, responsible for the PiZZ phenotype, is a proven genetic causal factor. This deficit concerns $1-3 \%$ of patients with COPD [48] and is expressed as a clinical picture of panlobular emphysema. Identification of simple nucleotide polymorphisms in the six haplotypes of the SERPINA 1 gene, which controls synthesis of $\alpha_{1}$-antitrypsin, means that this gene is considered to be an important causal factor in COPD [49].

Numerous other gene candidates have been studied, in particular genes coding for metalloproteinase of the extracellular matrix (MMP). Thus, MMP-9 is involved in the deterioration of components of the extracellular matrix such as gelatin, the collagens (IV, V, XI and XVII) and elastin. It has been shown that a polymorphism of MMP-9 (C-1562T) is associated with upper lung dominant emphysema $[50,51]$. In addition, a genetic predisposition for proteolysis of elastin in connection with the expression of a variant of the terminal exon in human elastin has been described for patients with severe COPD [52]. The interest shown in the gene coding for phospholipase $A_{2}$, a protein involved in the metabolism of fatty acids, is related to the fact that the plasma concentration of this enzyme is high in a certain number of inflammatory diseases [53]. The weight loss observed in some patients with COPD is thought to be related to the expression of variants of the subfamily of phospholipase $A_{2}$ belonging to group II [54]. Finally, it is necessary to note the associations described between COPD and various genetic polymorphisms: microsomal epoxide hydrolase, glutathione $S$ transferase, haemoxygenase-1 and tumour necrosis factor [55].

Systematic collections of blood samples for genetic measures could be useful in COPD epidemiological studies, and this needs to be further explored in future.

\section{Occupational exposure}

The risk attributable to occupational exposure in COPD has been estimated at 19\%, and for nonsmokers at 31\%. For nonsmokers, the principal areas of exposure are to be found in the rural environment, where subjects are exposed to a significant level of organic particles (vegetable dust, and bacterial or fungal toxins), in the textile industry, where subjects are exposed to a high level of plant dust (e.g. cotton dust) and in the industrial environment (mining, smelter plants and iron and steel industry, the wood industry and the building trade) [56]. The contribution of occupational exposures to COPD and, in particular, their potential interaction with cigarette smoking remains underappreciated. Joint exposure to both smoking and occupational factors has been found to markedly increase the risk of COPD [57].

\section{Air pollution}

Exposure to pollution inside the home, in particular in developing countries, is an important risk for COPD (risk accounting for $35 \%$ of cases), due to exposure to smoke when cooking or to the method of heating in badly ventilated housing, in particular for females. In China, the prevalence of COPD in nonsmoking females is thought to be three times higher in rural environments in comparison with females living in urban environments who are not thus exposed [58]. The role of air pollution in terms of risk factors is not well known. Its impact as an aggravating factor has been shown in patients with the most severe forms of COPD during peaks in air pollution [59-61].

Recently, a significant effect of long-term exposure to airborne particles on the risk of death was found in a large multi-city study of elderly subjects discharged alive following an admission for COPD [62].

Validity of environmental measurement is crucial and reconstructing individual exposure with traffic air pollutant dispersion models remains an important challenge in epidemiology studies [63].

\section{Age}

The prevalence of COPD increases with age [15]. In the course of life, there is a physiological decline in respiratory function which begins around the age of 30-40 yrs.

Because of the increase in life expectancy in developed countries, the proportion of older subjects with COPD also increases.

\section{Sex}

From an epidemiological point of view, males were classically more at risk of developing COPD in comparison with females because of their smoking habits. Progressively, however, and depending on the country, females who smoke as much as males seem to have an equivalent risk of developing COPD. 
Risk factors

Tobacco exposure in utero Genetic factors

Nutrition

Sex

Socio-economic status

\section{Risk factors}

Tobacco exposure in utero

Active smoking

Genetic factors

Nutrition

Socio-economic status

Bronchial hyperreactivity

Risk factors

Tobacco exposure in utero

Active smoking

Genetic factors

Occupational exposure

Nutrition

Socio-economic status

Bronchial hyperreactivity

\section{Risk factors}

Tobacco exposure in utero

Active smoking

Genetic factors

Occupational exposure

Nutrition

Socio-economic status

Bronchial hyperreactivity

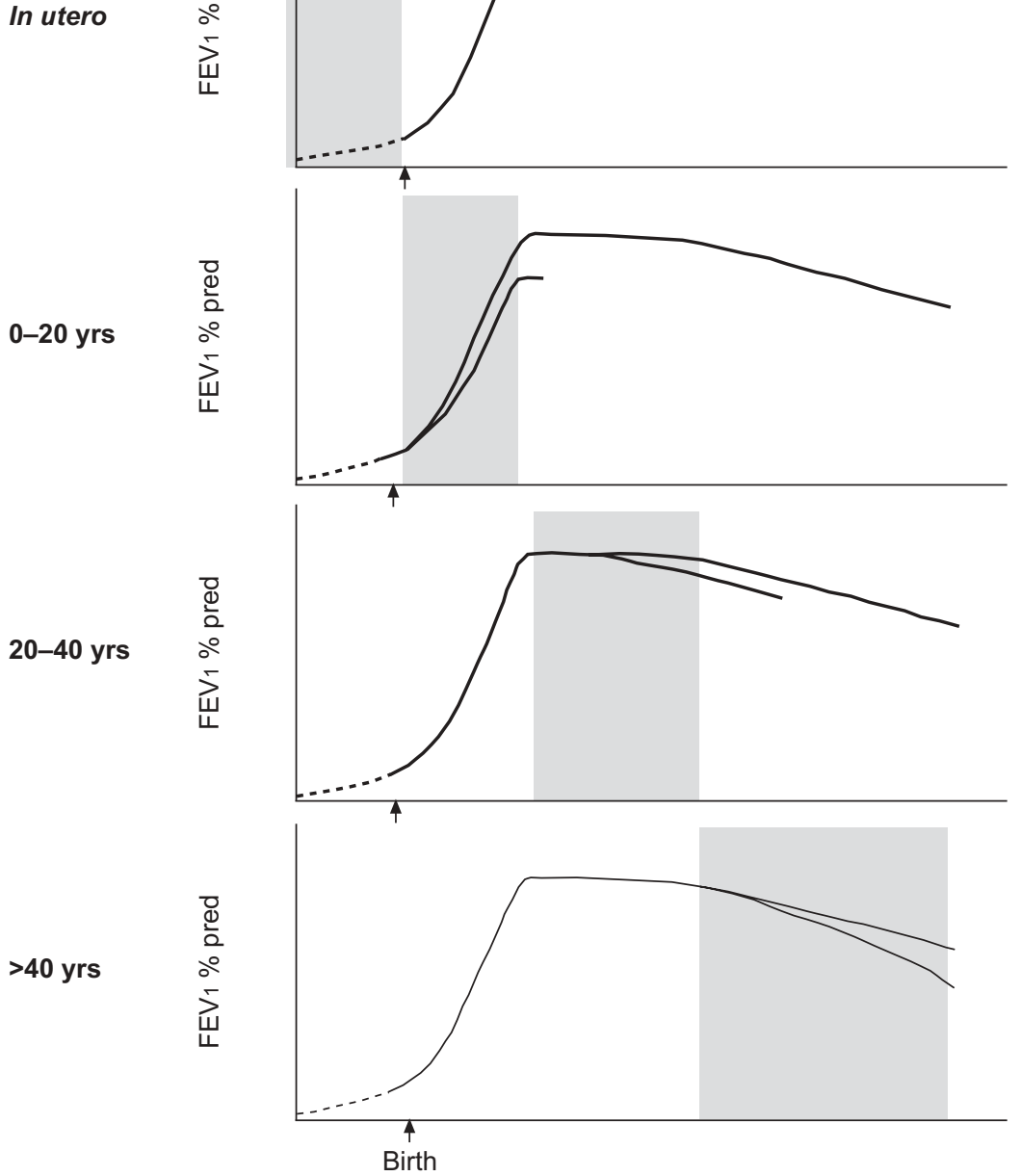

FIGURE 3. Impact of risk factors in the occurrence of chronic obstructive pulmonary disease. FEV1: forced expiratory volume in $1 \mathrm{~s}$; \% pred: \% predicted. Proposal for a theoretical model adapted from RIJCKEN and BRITTON [15].

Whether females are more at risk of developing COPD when they undertake similar smoking habits to their male counterparts is still under debate [64, 65].

\section{Infections}

Infections seem to play an important role in the occurrence of COPD, depending on age. During childhood, exposure to infections could alter the respiratory function of a child [66]. As an adult, the repeated occurrence of exacerbations which are viral or bacterial in origin could also contribute to lung function decline [67].

People with early life disadvantage had permanently lower lung function, no catch-up with age but slightly larger lung function decline, and substantially increased COPD risk. The impact of childhood disadvantage was as large as that of heavy smoking [68].

As is the case for the gastroduodenal ulcer and colonisation by Helicobacter pylori, some authors have suggested that the onset of COPD might be facilitated by a latent adenoviral infection. Through its interaction with DNA, the adenoviral protein E1A assists recruitment of numerous transcription factors that cause activation of pro-inflammatory genes [69]. In addition, concentration of the protein E1A in lung tissue is greater for patients who are smokers affected by COPD, in comparison with patients who are smokers but who have not developed the disease [70]. These studies are corroborated by experimental work using the transfection of human epithelial calls by the protein E1A, which induces activation of the proinflammatory transcription factor nuclear factor- $\mathrm{\kappa B}$ and the production of cytokines such as interleukin-8 and transforming growth factor (TGF)- $\beta[71,72]$.

\section{Bronchial hyperreactivity}

Asthmatic smokers have an increased risk of decline in respiratory function, in comparison with subjects who are not asthmatic. Whether bronchial hyperreactivity is a factor in the development of COPD is still under debate [73].

\section{Social and economic factors}

Populations living in disadvantaged social and economic conditions are more at risk of developing COPD after smoking 
is taken into account [74]. However, these criteria probably cover various risk factors, such as diet [75], the risk of infection and occupational exposure. Since these factors exist from childhood, they could have an impact on adult respiratory function [76].

\section{Conclusion}

To conclude, the various risk factors mentioned above could have a different impact on respiratory function, depending on the age of the subject. Respiratory function evolves in several main stages, a development stage which takes place in utero, a pulmonary growth stage which continues to young adulthood (20 yrs), a maturity stage between the ages of 20 and $30 \mathrm{yrs}$ and a stage of physiological decline, which is thought to begin after the age of 40 yrs. The possibility of cumulated risks should also be taken into account, because of the simultaneous presence or absence of these various risk factors in the same individual, showing a possible variability of natural history of COPD (fig. 3).

\section{STATEMENT OF INTEREST}

None declared.

\section{REFERENCES}

1 Snider GL. Distinguishing among asthma, chronic bronchitis, and emphysema. Chest 1985; 87: Suppl. 1, 35S-39S.

2 MacNee W. Pathogenesis of chronic obstructive pulmonary disease. Proc Am Thorac Soc 2005; 2: 258-266.

3 Toren K, Brisman J, Jarvholm B. Asthma and asthma-like symptoms in adults assessed by questionnaires. A literature review. Chest 1993; 104: 600-608.

4 de Marco R, Zanolin ME, Accordini S, et al. A new questionnaire for the repeat of the first stage of the European Community Respiratory Health Survey: a pilot study. Eur Respir J 1999; 14: 1044-1048.

5 Global Initiative for Chronic Obstructive Lung Disease. Global Strategy for Diagnosis, Management and Prevention of COPD. Bethesda/Geneva, National Institutes of Health/World Health Organization, 2007. Available from: www.goldcopd.org

6 Shirtcliffe P, Weatherall M, Marsh S, et al. COPD prevalence in a random population survey: a matter of definition. Eur Respir J 2007; 30: 232-239.

7 Schermer TR, Smeele IJ, Thoonen BP, et al. Current clinical guideline definitions of airflow obstruction and COPD overdiagnosis in primary care. Eur Respir J 2008; 32: 945-952.

8 Hansen JE, Ulubay G, Chow BF, et al. Mixed-expired and end-tidal $\mathrm{CO}_{2}$ distinguish between ventilation and perfusion defects during exercise testing in patients with lung and heart diseases. Chest 2007; 132: 977-983.

9 Swanney MP, Ruppel G, Enright PL, et al. Using the lower limit of normal for the FEV1/FVC ratio reduces the misclassification of airway obstruction. Thorax 2008; 63: 1046-1051.

10 Buist AS, McBurnie MA, Vollmer WM, et al. International variation in the prevalence of COPD (the BOLD Study): a population-based prevalence study. Lancet 2007; 370: 741-750.

11 Vollmer WM, Gislason T, Burney P, et al. Comparison of spirometry criteria for the diagnosis of COPD: results from the BOLD study. Eur Respir J 2009; 34: 588-597.

12 Pellegrino RC Viegi G, Brusasco V, et al. Interpretative strategies for lung function tests. Eur Respir J 2005; 26: 948-968.

13 Roche N, Dalmay F, Perez T, et al. FEV1/FVC and FEV1 for the assessment of chronic airflow obstruction in prevalence studies: do prediction equations need revision? Respir Med 2008; 102: 15681574 .
14 Halbert RJ, Natoli JL, Gano A, et al. Global burden of COPD: systematic review and meta-analysis. Eur Respir J 2006; 28: 523-532.

15 Epidemiology of chronic obstructive pulmonary disease. In: Postma DS, Siafakas N, eds. Management of Chronic Obstructive Pulmonary Disease. Eur Respir Mon 1998; 7: 41-73.

16 Chan-Yeung M, Ait-Khaled N, White N, et al. The burden and impact of COPD in Asia and Africa. Int J Tuberc Lung Dis 2004; 8: 2-14.

17 Menezes AM, Perez-Padilla R, Jardim JR, et al. Chronic obstructive pulmonary disease in five Latin American cities (the PLATINO study): a prevalence study. Lancet 2005; 366: 1875-1881.

18 Huchon GJ, Vergnenegre A, Neukirch F, et al. Chronic bronchitis among French adults: high prevalence and underdiagnosis. Eur Respir J 2002; 20: 806-812.

19 de Marco R, Accordini S, Cerveri I, et al. Incidence of chronic obstructive pulmonary disease in a cohort of young adults according to the presence of chronic cough and phlegm. Am J Respir Crit Care Med 2007; 175: 32-39.

20 Price DB, Tinkelman DG, Nordyke RJ, et al. Scoring system and clinical application of COPD diagnostic questionnaires. Chest 2006; 129: 1531-1539.

21 Zielinski J, Bednarek M, Gorecka D, et al. Increasing COPD awareness. Eur Respir J 2006; 27: 833-852.

22 Carrasco Garrido P, de Miguel Diez J, Rejas Gutierrez J, et al. Negative impact of chronic obstructive pulmonary disease on the health-related quality of life of patients. Results of the EPIDEPOC study. Health Qual Life Outcomes 2006; 4: 31.

23 Loddenkemper R, Gibson GJ, Sibille Y. The burden of lung disease in Europe: why a European White Book on lung disease? Eur Respir J 2003; 22: 869.

24 Detournay B, Pribil C, Fournier M, et al. The SCOPE study: healthcare consumption related to patients with chronic obstructive pulmonary disease in France. Value Health 2004; 7: 168-174.

25 Chapman KR, Mannino DM, Soriano JB, et al. Epidemiology and costs of chronic obstructive pulmonary disease. Eur Respir J 2006; 27: 188-207.

26 Sin DD, Anthonisen NR, Soriano JB, et al. Mortality in COPD: role of comorbidities. Eur Respir J 2006; 28: 1245-1257.

27 Boutin-Forzano S, Moreau D, Kalaboka S, et al. Reported prevalence and co-morbidity of asthma, chronic bronchitis and emphysema: a pan-European estimation. Int J Tuberc Lung Dis 2007; 11: 695-702.

28 Viegi G, Pistelli F, Sherrill DL, et al. Definition, epidemiology and natural history of COPD. Eur Respir J 2007; 30: 993-1013.

29 Barr RG, Celli BR, Mannino DM, et al. Comorbidities, patient knowledge, and disease management in a national sample of patients with COPD. Am J Med 2009; 122: 348-355.

30 European Respiratory Society/European Lung Foundation European Lung White Book. The First Comprehensive Survey on Respiratory Health in Europe. Loddenkemper R, Gibson GJ, Sibille Y, eds. Sheffield, ERSJ, 2003.

31 Niu SR, Yang GH, Chen ZM, et al. Emerging tobacco hazards in China: 2. Early mortality results from a prospective study. BMJ 1998; 317: 1423-1424.

32 Mannino DM, Buist AS, Petty TL, et al. Lung function and mortality in the United States: data from the First National Health and Nutrition Examination Survey follow up study. Thorax 2003; 58: 388-393.

33 Celli BR, Cote CG, Marin JM, et al. The body-mass index, airflow obstruction, dyspnea, and exercise capacity index in chronic obstructive pulmonary disease. N Engl J Med 2004; 350: 1005-1012.

34 Fuhrman C JE, Nicolau J, Eilstein D, et al. Deaths from chronic obstructive pulmonary disease in France, 1979-2002: a multiple cause analysis. Thorax 2006; 61: 930-934.

35 Anthonisen NR, Skeans MA, Wise RA, et al. The effects of a smoking cessation intervention on 14.5-year mortality: a randomized clinical trial. Ann Intern Med 2005; 142: 233-239. 
36 O'Reilly P, Bailey W. Long-term continuous oxygen treatment in chronic obstructive pulmonary disease: proper use, benefits and unresolved issues. Curr Opin Pulm Med 2007; 13: 120-124.

37 Fletcher $\mathrm{C}$, Peto R. The natural history of chronic airflow obstruction. Br Med J 1977; 1: 1645-1648.

38 Gilliland FD, Li YF, Dubeau L, et al. Effects of glutathione Stransferase M1, maternal smoking during pregnancy, and environmental tobacco smoke on asthma and wheezing in children. Am J Respir Crit Care Med 2002; 166: 457-463.

39 Keatings VM, Collins PD, Scott DM, et al. Differences in interleukin-8 and tumor necrosis factor- $\alpha$ in induced sputum from patients with chronic obstructive pulmonary disease or asthma. Am J Respir Crit Care Med 1996; 153: 530-534.

40 Lim S, Roche N, Oliver BG, et al. Balance of matrix metalloprotease-9 and tissue inhibitor of metalloprotease- 1 from alveolar macrophages in cigarette smokers. Regulation by interleukin-10. Am J Respir Crit Care Med 2000; 162: 1355-1360.

41 Capelli A, Di Stefano A, Gnemmi I, et al. Increased MCP-1 and MIP-1 $\beta$ in bronchoalveolar lavage fluid of chronic bronchitics. Eur Respir J 1999; 14: 160-165.

42 Takizawa H, Tanaka M, Takami K, et al. Increased expression of transforming growth factor-beta1 in small airway epithelium from tobacco smokers and patients with chronic obstructive pulmonary disease (COPD). Am J Respir Crit Care Med 2001; 163: 1476-1483.

43 Chung KF. The role of airway smooth muscle in the pathogenesis of airway wall remodeling in chronic obstructive pulmonary disease. Proc Am Thorac Soc 2005; 2: 347-354.

44 Gadek JE, Fells GA, Crystal RG. Cigarette smoking induces functional antiprotease deficiency in the lower respiratory tract of humans. Science 1979; 206: 1315-1316.

45 MacNee W, Rahman I. Is oxidative stress central to the pathogenesis of chronic obstructive pulmonary disease? Trends Mol Med 2001; 7: 55-62.

46 Molfino NA. Genetics of COPD. Chest 2004; 125: 1929-1940.

47 Mannino DM, Watt G, Hole D, et al. The natural history of chronic obstructive pulmonary disease. Eur Respir J 2006; 27: 627-643.

48 Stoller JK, Aboussouan LS. Alpha1-antitrypsin deficiency. Lancet 2005; 365: 2225-2236.

49 Chappell S, Daly L, Morgan K, et al. Cryptic haplotypes of SERPINA1 confer susceptibility to chronic obstructive pulmonary disease. Hum Mutat 2006; 27: 103-109.

50 Ito I, Nagai S, Handa T, et al. Matrix metalloproteinase-9 promoter polymorphism associated with upper lung dominant emphysema. Am J Respir Crit Care Med 2005; 172: 1378-1382.

51 Taggart CC, Greene CM, Carroll TP, et al. Elastolytic proteases: inflammation resolution and dysregulation in chronic infective lung disease. Am J Respir Crit Care Med 2005; 171: 1070-1076.

52 Kelleher CM, Silverman EK, Broekelmann T, et al. A functional mutation in the terminal exon of elastin in severe, early-onset chronic obstructive pulmonary disease. Am J Respir Cell Mol Biol 2005; 33: 355-362.

53 Triggiani M, Granata F, Giannattasio G, et al. Secretory phospholipases $\mathrm{A}_{2}$ in inflammatory and allergic diseases: not just enzymes. J Allergy Clin Immunol 2005; 116: 1000-1006.

54 Takabatake N, Sata M, Inoue S, et al. A novel polymorphism in secretory phospholipase $\mathrm{A}_{2}$-IID is associated with body weight loss in chronic obstructive pulmonary disease. Am J Respir Crit Care Med 2005; 172: 1097-1104.

55 Coultas DB. Health effects of passive smoking. 8. Passive smoking and risk of adult asthma and COPD: an update. Thorax 1998; 53: 381-387.

56 Hnizdo E, Sullivan PA, Bang KM, et al. Association between chronic obstructive pulmonary disease and employment by industry and occupation in the US population: a study of data from the Third National Health and Nutrition Examination Survey. Am J Epidemiol 2002; 156: 738-746.

57 Blanc PD, Iribarren C, Trupin L, et al. Occupational exposures and the risk of COPD: dusty trades revisited. Thorax 2009; 64: 6-12.

58 Liu S, Zhou Y, Wang X, et al. Biomass fuels are the probable risk factor for chronic obstructive pulmonary disease in rural South China. Thorax 2007; 62: 889-897.

59 Wordley J, Walters S, Ayres JG. Short term variations in hospital admissions and mortality and particulate air pollution. Occup Environ Med 1997; 54: 108-116.

60 Morgan G, Corbett S, Wlodarczyk J. Air pollution and hospital admissions in Sydney, Australia, 1990 to 1994. Am J Public Health 1998; 88: 1761-1766.

61 Ko FW, Tam W, Wong TW, et al. Temporal relationship between air pollutants and hospital admissions for chronic obstructive pulmonary disease in Hong Kong. Thorax 2007; 62: 780-785.

62 Zanobetti A, Bind MA, Schwartz J. Particulate air pollution and survival in a COPD cohort. Environ Health 2008; 7: 48.

63 Kostrzewa A, Reungoat P, Raherison C. Validity of a traffic air pollutant dispersion model to assess exposure to fine particles. Environ Res 2009; 109: 651-656.

64 Mannino DM, Buist AS. Global burden of COPD: risk factors, prevalence, and future trends. Lancet 2007; 370: 765-773.

65 Prescott E, Bjerg AM, Andersen PK, et al. Gender difference in smoking effects on lung function and risk of hospitalization for COPD: results from a Danish longitudinal population study. Eur Respir J 1997; 10: 822-827.

66 Barker DJ, Godfrey KM, Fall C, et al. Relation of birth weight and childhood respiratory infection to adult lung function and death from chronic obstructive airways disease. BMJ 1991; 303: 671-675.

67 Donaldson GC, Seemungal TA, Bhowmik A, et al. Relationship between exacerbation frequency and lung function decline in chronic obstructive pulmonary disease. Thorax 2002; 57: 847-852.

68 Svanes C, Sunyer J, Plana E, et al. Early life origins of chronic obstructive pulmonary disease. Thorax 2009; [Epub ahead of print DOI: $10.1136 /$ thx.2008.112136]

69 Keicho N, Elliott WM, Hogg JC, et al. Adenovirus E1A gene dysregulates ICAM-1 expression in transformed pulmonary epithelial cells. Am J Respir Cell Mol Biol 1997; 16: 23-30.

70 Elliott WM, Hayashi S, Hogg JC. Immunodetection of adenoviral E1A proteins in human lung tissue. Am J Respir Cell Mol Biol 1995; 12: $642-648$.

71 Gilmour PS, Rahman I, Hayashi S, et al. Adenoviral E1A primes alveolar epithelial cells to $\mathrm{PM}_{10}$-induced transcription of interleukin8. Am J Physiol Lung Cell Mol Physiol 2001; 281: L598-L606.

72 Higashimoto Y, Elliott WM, Behzad AR, et al. Inflammatory mediator mRNA expression by adenovirus E1A-transfected bronchial epithelial cells. Am J Respir Crit Care Med 2002; 166: 200-207.

73 Lange P, Parner J, Vestbo J, et al. A 15-year follow-up study of ventilatory function in adults with asthma. N Engl J Med 1998; 339: 1194-1200.

74 Shohaimi S, Welch A, Bingham S, et al. Area deprivation predicts lung function independently of education and social class. Eur Respir J 2004; 24: 157-161.

75 Shohaimi S, Bingham S, Welch A, et al. Occupational social class, educational level and area deprivation independently predict plasma ascorbic acid concentration: a cross-sectional population based study in the Norfolk cohort of the European Prospective Investigation into Cancer (EPIC-Norfolk). Eur J Clin Nutr 2004; 58: 1432-1435.

76 Lawlor DA, Ebrahim S, Davey Smith G. Association between selfreported childhood socioeconomic position and adult lung function: findings from the British females's Heart and Health Study. Thorax 2004; 59: 199-203. 